\title{
Determinação da fragilidade ambiental de uma bacia hidrográfica pertencente ao município de Presidente Prudente, SP
}

\author{
Determination of the environmental fragility of a hydrographic basin belonging to the municipality \\ of Presidente Prudente, SP
}

\author{
Mariane Moura Andrade ${ }^{1 *}$, Danieli Regina Klein ${ }^{1}$, Sandra Mara Krefta ${ }^{1}$ \& André Gonçalves Vieira ${ }^{2}$ \\ ${ }^{1}$ Universidade do Estado de Santa Catarina, Lages, SC, Brasil. *Autor para correspondência: enairamma@hotmail.com. \\ ${ }^{2}$ Universidade Estadual Paulista Júlio de Mesquita Filho, Presidente Prudente, SP, Brasil.
}

Submissão: 11/10/2016 / Aceite: 09/05/2018

\begin{abstract}
RESUMO
Os estudos da fragilidade dos ambientes são significativos e importantes para o planejamento ambiental e territorial, pois se trata de uma ferramenta que analisa e identifica ambientes em relação aos seus distintos níveis de vulnerabilidade. A carta de fragilidade auxilia em um diagnóstico aonde se pode fazer a correção dos problemas presentes e intervir em ações futuras. O presente trabalho foi elaborado com o objetivo de determinar a fragilidade ambiental de uma bacia hidrográfica da cidade de Presidente Prudente, SP, que não havia sido estudada anteriormente. Essa metodologia objetiva identificar áreas que apresentam maiores ou menores fragilidades, resultantes de pressões antrópicas advindas dos diferentes tipos de uso e ocupação do solo. Através deste estudo foi observado que esta bacia apresenta predomínio de fragilidade potencial média, seguida pela fragilidade potencial forte. Esse resultado indica grande predomínio de vegetação herbácea, solos rasos e áreas inadequadas para a implantação de atividades antrópicas devido à alta declividade.
\end{abstract}

PALAVRAS-CHAVE: planejamento territorial, vulnerabilidade ambiental, bacia do Coqueiro.

\begin{abstract}
The studies of the fragility of the environments are significant and important for the environmental and territorial planning, since it is a tool that analyzes and identifies environments in relation to their different levels of vulnerability. The letter of fragility assists in a diagnosis where the problems can be corrected and intervene in future actions. The present work was elaborated with the objective of determining the environmental fragility of a hydrographic basin of the city of Presidente Prudente, SP, that had not been previously studied. This methodology aims to identify areas that present greater or lesser fragilities, resulting from anthropic pressures arising from different types of land use and occupation. Through this study, it observed that this basin presents a predominance of medium potential fragility, followed by strong potential fragility. This result indicates a large predominance of herbaceous vegetation, shallow soils and areas unsuitable for the implantation of anthropic activities due to the high slope.

KEYWORDS: territorial planning, environmental vulnerability, watershed of Coqueiro.
\end{abstract}

\section{INTRODUÇÃO}

Conforme retrataram GONÇALVES et al. (2011), há uma preocupação em relação a influência antrópica no ambiente, principalmente em relação as bacias hidrográficas. Diversas são as pesquisas desenvolvidas, que objetivam em quantificar e qualificar impactos da ocupação territorial, nos diferentes elementos que compõe o meio ambiente. Desta forma, é essencial conhecer a capacidade e limitação no uso do meio e suas características.

As bacias hidrográficas consistem em unidades de manejo ambiental, que apresentam particularidades como relevo, geologia e tipo de solo, o que caracteriza a vulnerabilidade natural a que uma bacia está submetida.

Nesse sentido, a ação antrópica exercida nesses ambientes, ou seja, fatores externos de ocorrência não natural permitem aferir o nível de degradação causada, aplicando, por exemplo, estudos de fragilidade ambiental em bacias hidrográficas, os quais constituem um importante instrumento no planejamento 
ambiental estratégico (GONÇALVES et al. 2011).

As avaliações da fragilidade ambiental são fundamentadas em fatores como declividade, solo, potencial de erosão das chuvas e a cobertura vegetal, sendo imprescindíveis ao planejamento ambiental.

SPÖRL (2001) afirma que, ao conhecer os níveis de fragilidade presente em uma bacia hidrográfica, através da conexão de diversas variáveis que interferem nas potencialidades dos recursos naturais, é possível compreender a realidade obtendo uma visão clara das opções que se tornam mais apropriadas para o uso da terra.

O mapa de fragilidade ambiental compõe uma das principais ferramentas empregadas pelos órgãos públicos na elaboração do planejamento territorial ambiental. As potencialidades podem ser avaliadas por meio do mapeamento da fragilidade ambiental de forma integrada, unificando suas características naturais com suas restrições. Essa metodologia da fragilidade empírica foi proposta por ROSS (1994) onde se fundamenta no princípio de que a natureza apresenta funcionalidade intrínseca entre seus componentes físicos e bióticos (KAWAKUBO et al. 2005).

Com isso, fica evidente que os estudos de fragilidade ambiental proporcionam melhor definição das diretrizes e ações a serem implantadas no espaço físico-territorial, servindo de base para o zoneamento ambiental e fornecendo subsídios à gestão do território (SPÖRL \& ROSS 2004).

Assim, o estudo teve por objetivo determinar a fragilidade ambiental de uma bacia hidrográfica denominada "Coqueiro" pertencente ao município de Presidente Prudente, SP, considerando atributos geoambientais, como uso do solo, cobertura vegetal, declividade e curvatura.

\section{MATERIAL E MÉTODOS}

O estudo foi desenvolvido no município de Presidente Prudente, que abrange uma área de 562,107 $\mathrm{km}^{2}$ de superfície localizada na região do Sudoeste do Estado de São Paulo. O município está localizado nas coordenadas geográficas de latitude $22^{\circ} 07^{\prime} 04^{\prime \prime}$ longitude $51^{\circ} 22^{\prime} 57^{\prime \prime}$ e com altitude de 472 metros (IBGE 2010). A Figura 1 mostra a localização da região administrativa do município de Presidente Prudente.

Figura 1. Localização do Município de Presidente Prudente, SP, Brasil.

Figure 1. Location of the Municipality of Presidente Prudente, SP, Brazil.

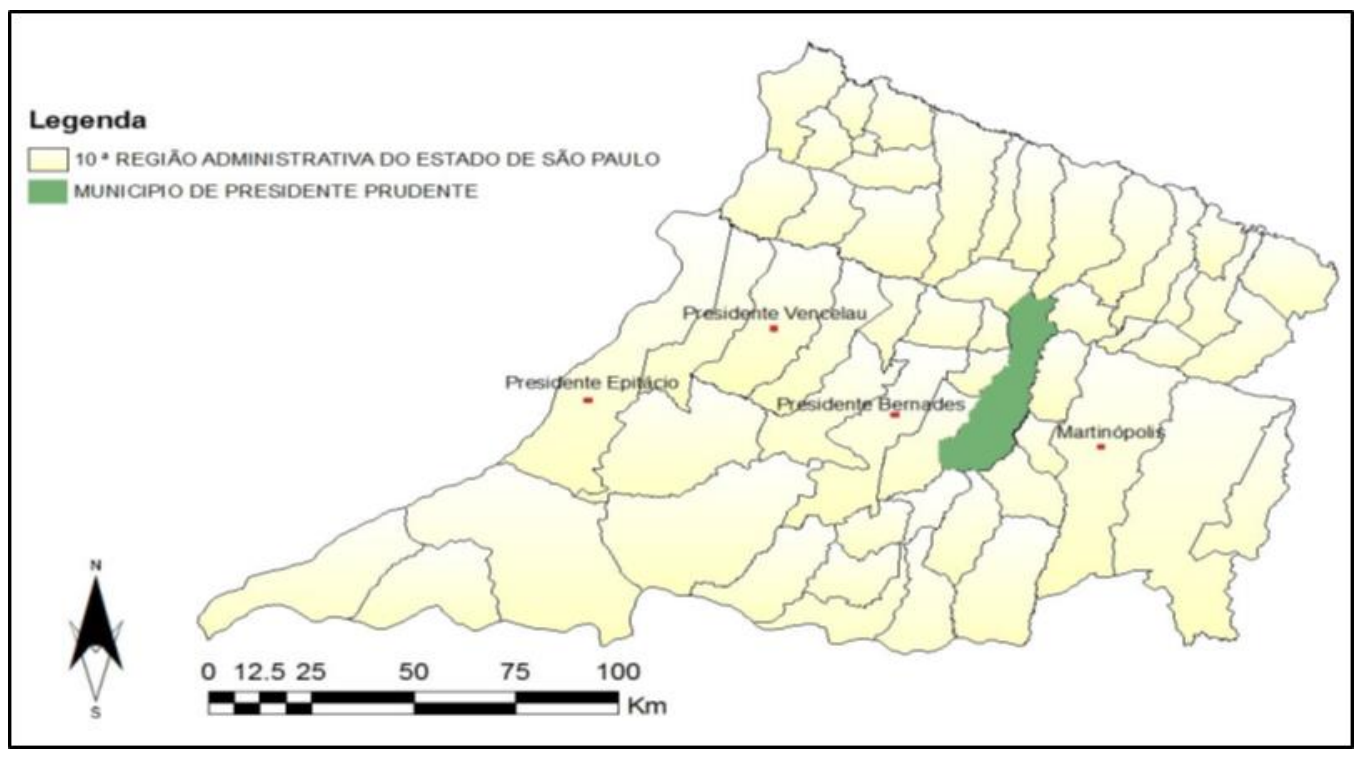

De acordo com MONTEIRO (1973), Presidente Prudente possui características climáticas de invernos secos com pouca precipitação, que sofre ação predominante dos sistemas polares, e verões chuvosos devido ao predomínio dos sistemas tropicais. BOIN (2000) salienta ainda que a precipitação anual na região varia entre 1200 a $1500 \mathrm{~mm}$, enquanto a temperatura média anual permanece acima de $22{ }^{\circ} \mathrm{C}$.

Presidente Prudente está localizada na bacia hidrográfica do rio Paraná, tendo em seu território várias sub-bacias constituídas de pequenos e médios córregos com papéis importantes em sua configuração, e sendo drenados pelos córregos do Veado e do Cedro, pertencentes à bacia do rio Santo Anastácio; e pelo córrego da Onça e rio Mandaguari, que pertencem à bacia do rio do Peixe. O córrego do Coqueiro foi o rio selecionado para elaboração do mapa de fragilidade, conforme observa-se na Figura 2, sendo este córrego afluente do rio Mandaguari. 
Foram utilizadas imagens do Projeto TOPODATA (Banco de dados geomorfométricos do Brasil) provenientes do INPE. Os produtos do projeto TOPODATA são derivados do processo de refinamento das imagens SRTM (Shuttle Radar Topography Mission) que transforma sua resolução espacial original, de $\sim 90 \mathrm{~m}$ para $\sim 30 \mathrm{~m}$, utilizando o método de krigagem, além de diversas análises geomorfométricas. Fez-se também pesquisas bibliográficas sobre a fragilidade ambiental, como suporte para elaboração deste trabalho. Para confecção do mapa foi utilizado o ArcGIS adquirido pelo laboratório de geoprocessamento da Universidade Estadual Paulista (UNESP) de Presidente Prudente, SP.

Os procedimentos foram baseados no conceito de ROSS (1994) com a metodologia de análise de Fragilidade Ambiental, conhecida no âmbito da Geografia para estudos de fragilidade. Este método é de ampla importância para análise ambiental e planejamento, pois, a partir dele pode-se identificar a vulnerabilidade e as potencialidades dos diferentes ambientes.

Figura 2. Identificação da área do córrego do Coqueiro, em Presidente prudente, SP, Brasil. Figure 2. Identification of from the Coqueiro stream, in Presidente prudente, SP, Brazil.

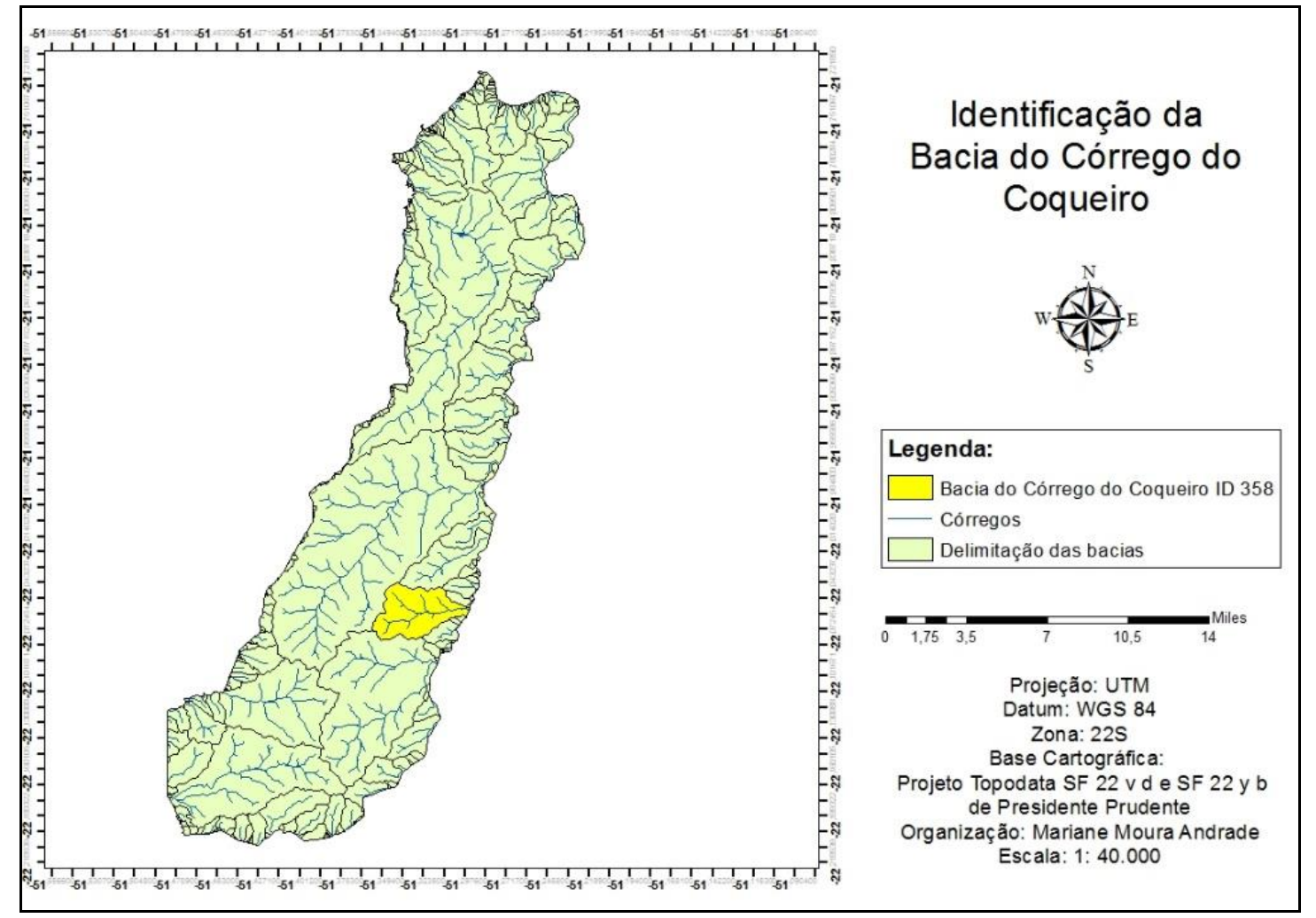

Para elaboração do mapa de Fragilidade foram seguidos diversos passos, sendo o primeiro a inserção das imagens no programa através do comando moisaic. Após, foi transformado o raster de 32 bits para 16 bits através do comando copy raster, além de definir a projeção em WGS 84 .

Posteriormente foi recortada a imagem com o objetivo de transformá-la no mesmo tamanho do município de Presidente Prudente, por meio do comando extract by mask. A imagem foi tratada utilizando uma ferramenta que preenche e corta os pixels de acordo com a sua necessidade pelo comando fill. Este preenche a superfície do raster removendo pequenas imperfeições. Após foi aplicado o flow direction e o flow accumulation que resultou em um raster de fluxo acumulado para cada célula.

Assim, foi possível classificar os fluxos da bacia pelo comando Stream Order, com método Strahler. A transformação do raster em feature pelo comando strem to feature foi separada a bacia através do comando Hidrology - Basin. Adicionou-se uma classificação de cores a bacia, sendo assim, convertidos raster em polígonos, para escolher a bacia do presente estudo e recortá-la das demais bacias.

Para a interpretação das variáveis, foram elaborados mapas a partir de um shape disponibilizado pela UNESP, Presidente Prudente, tais como:

- Classificação de solos: a classificação de solos se deu através de um shape pré disponibilizado pela UNESP, Presidente Prudente de solos de toda a bacia, onde a partir disso foi utilizado o comando clip para cortar a sub bacia do córrego do coqueiro.

- Uso do solo: para a confecção do mapa do uso do solo foi gerado igualmente ao de classificação de solos, sendo este já classificado as fragilidades conforme a classe de uso do solo. 
- Declividade: este mapa foi gerado a partir do mapa hipsométrico da imagem SRTM já adquirida, através do comando Slope pertencentes ao Arctoolbox - 3D analyst tools - raster surface foi possível gerar a declividade. Neste mapa foram empregadas cinco classes de declividade e suas fragilidades segundo ROSS (1994), possuindo categorias hierárquicas, tais como: muito fraca até $6 \%$, Fraca de 6 a $12 \%$, média de 12 a $20 \%$, forte de 20 a $30 \%$ e muito forte acima de $30 \%$. Após isso foi possível reclassificar usando o comando Reclass - Reclassify e adicionar as classes pertinentes na tabela de atributos.

- Curvatura: o mapa de curvatura foi criado a partir dos shapes de altimetria e drenagem já disponibilizados pela UNESP, sendo este recortado (clip) para a bacia em estudo, transformado tin e raster, e posteriormente utilizado o comando Fill para o preenchimento de pequenas imperfeições, ao final foi utilizado o comando curvature, e classificando o mapa através de três classes, côncavo, retilíneo e convexo. Posteriormente para o cruzamento da curvatura com a declividade foi adicionado na tabela de atributos às classes de declividade que compreende a fragilidade média, forte e muito forte e as classes de curvatura retilínea, convexa e côncava.

Assim, realizou-se o cruzamento dos dados de declividade e curvatura gerando a fragilidade do relevo, bem como, o cruzamento entre fragilidade do relevo, classificação e uso dos solos, sendo este gerado através da ferramenta Weighted overlay, gerando ao final o mapa de fragilidade ambiental.

\section{RESULTADOS E DISCUSSÃO}

Presidente Prudente possui características de vegetação da Floresta Estacional Semidecidual. Atributos de Estacional por apresentar duas estações do ano bem definidas (chuvosa e seca) e Semidecidual por apresentar porcentagem de árvores caducifólias peculiar desta formação florestal. Assim a vegetação da bacia é caracterizada como Floresta Estacionária Semidecidual, contida na classificação fisionômico-ecológico da formação ecológica do Sudeste Paulista de acordo com FRANCISCO (1989).

Conforme demonstra o mapa de fragilidade ambiental (Figura 3), constata-se predomínio de fragilidade potencial média, representado, por sua maioria, na cor amarela.

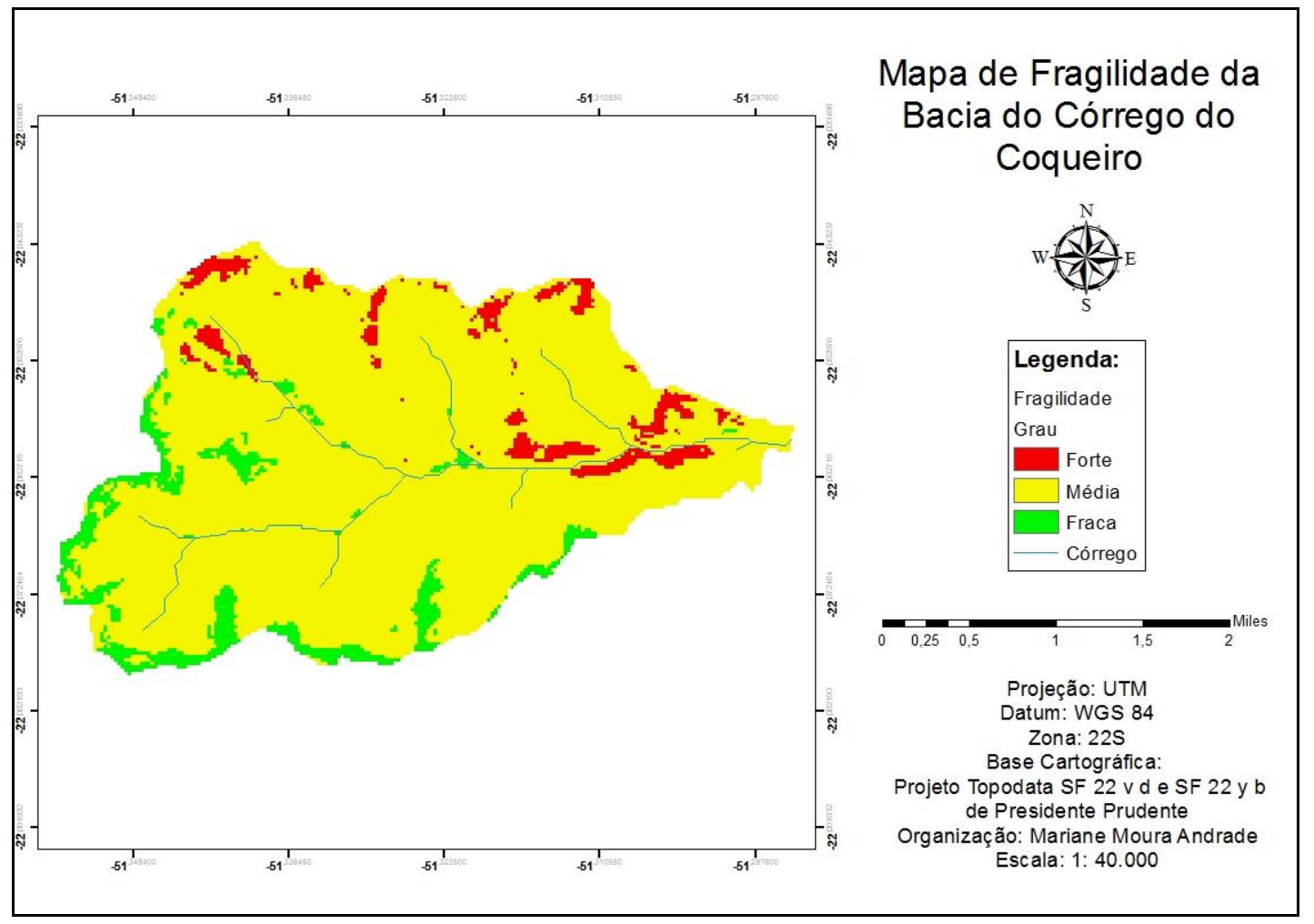

Figura 3. Graus da Fragilidade Ambiental da Bacia Hidrográfica do Córrego do Coqueiro. Presidente Prudente, SP, Brasil.

Figure 3. Degrees of the Environmental Fragility of the Coqueiro Stream Hydrographic Basin. Presidente Prudente, SP, Brazil.

As localidades de médio grau de dissecação do relevo, associados a solos de média vulnerabilidade, mostram que há predomínio de vegetação herbácea arbustiva e arbórea e solos rasos desenvolvidos, como os Argissolos (Figura 4). 
Esses solos por sua vez, estão associados em sua maioria aos relevos montanhosos com encostas suaves, que possuem declives médios e estão em constante ocorrência de processos de morfogênese e pedogênese (ROSS 1994). Nestas áreas são admissíveis que se desenvolvam atividades humanas, sendo estas acompanhadas por profissionais especializados e respeitando as áreas de preservação permanente.

O segundo grau mais evidente na Figura 3 é quanto à fragilidade potencial forte (indicada pela coloração vermelha), em que se constituem áreas inadequadas para a implantação de atividades antrópicas devido à média e alta declividade, como pode ser observado na Figura 5.

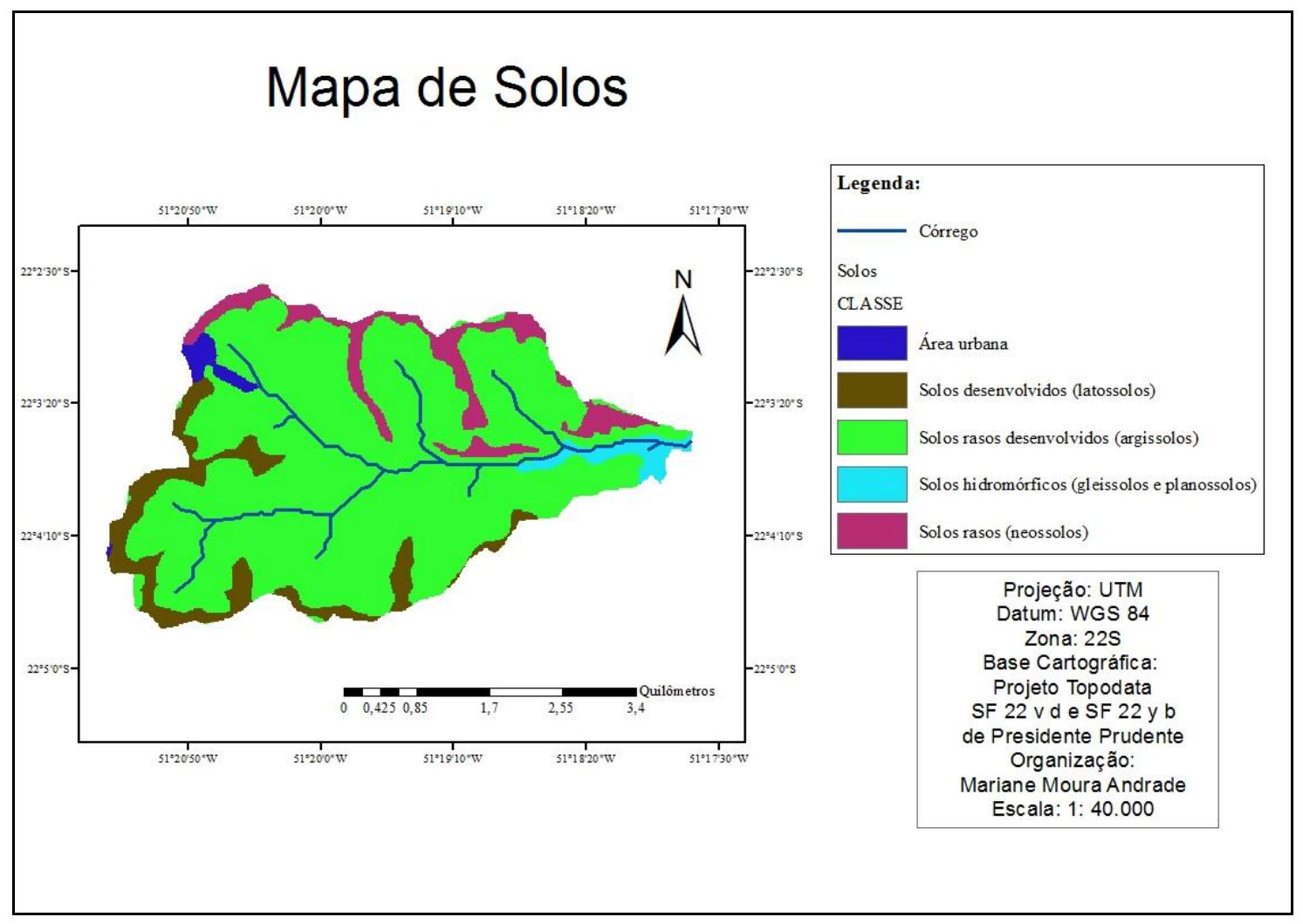

Figura 4. Classificação de Solos da Bacia Hidrográfica do Córrego do Coqueiro. Presidente Prudente, SP, Brasil.

Figure 4. Soil Classification of the Coqueiro Stream Hydrographic Basin. Presidente Prudente, SP, Brazil.

O mapa de curvatura nos mostra as áreas predominantes apresentadas pela coloração alaranjada forte e clara em sua maioria são vertentes convexas com declividade muito fraca e fraca (6 a 12\%) e côncava com declividade fraca e média (6 a 20\%), indicando baixa e média fragilidade ambiental Figura 6 ).

A cobertura vegetal é de extrema importância, visto que há solos vulneráveis à erosão representada no mapa pela cor vermelha, ou áreas construídas representadas pela cor amarela, como residências e demais dependências de chácaras e sítios, que causam a impermeabilização do solo (Figura 7). Além disso, o uso inadequado destas áreas pode levar a processos erosivos, sendo esses intensificados por efeitos climáticos, como a pluviosidade.

Alguns locais representados pela coloração verde na Figura 7, possuem fragilidade potencial fraca, os quais estão associados a solos de baixa vulnerabilidade e fraca dissecação do relevo. Essas áreas possuem melhor adaptação à produção agrícola e acolhimento de pessoas, não permitido ocorrerem em áreas de várzea ou de matas e florestas (MESSIAS et al. 2012).

Os latossolos indicados na Figura 4 representam solos de baixa vulnerabilidade, posicionam-se, principalmente, sobre os relevos de colinas, sendo pouco suscetíveis à erosão com fragilidade classificada como muito baixa, com boa drenagem e permeabilidade.

Dessa forma, apresenta fraca dissecação do relevo, representada pelas colorações verde escura e clara (Figura 5), e o uso do solo aponta a cobertura herbácea arbustiva e arbórea (Figura 7).

Os resultados do mapa de Fragilidade Ambiental apontam que há a predominância da fragilidade média na área avaliada. Esta classe está relacionada, sobretudo, ao predomínio de culturas e pastagens. De acordo com ROSS (1994), as pastagens possuem médio grau de proteção ao solo, enquanto os cultivos agrícolas apresentam baixo grau de proteção. 


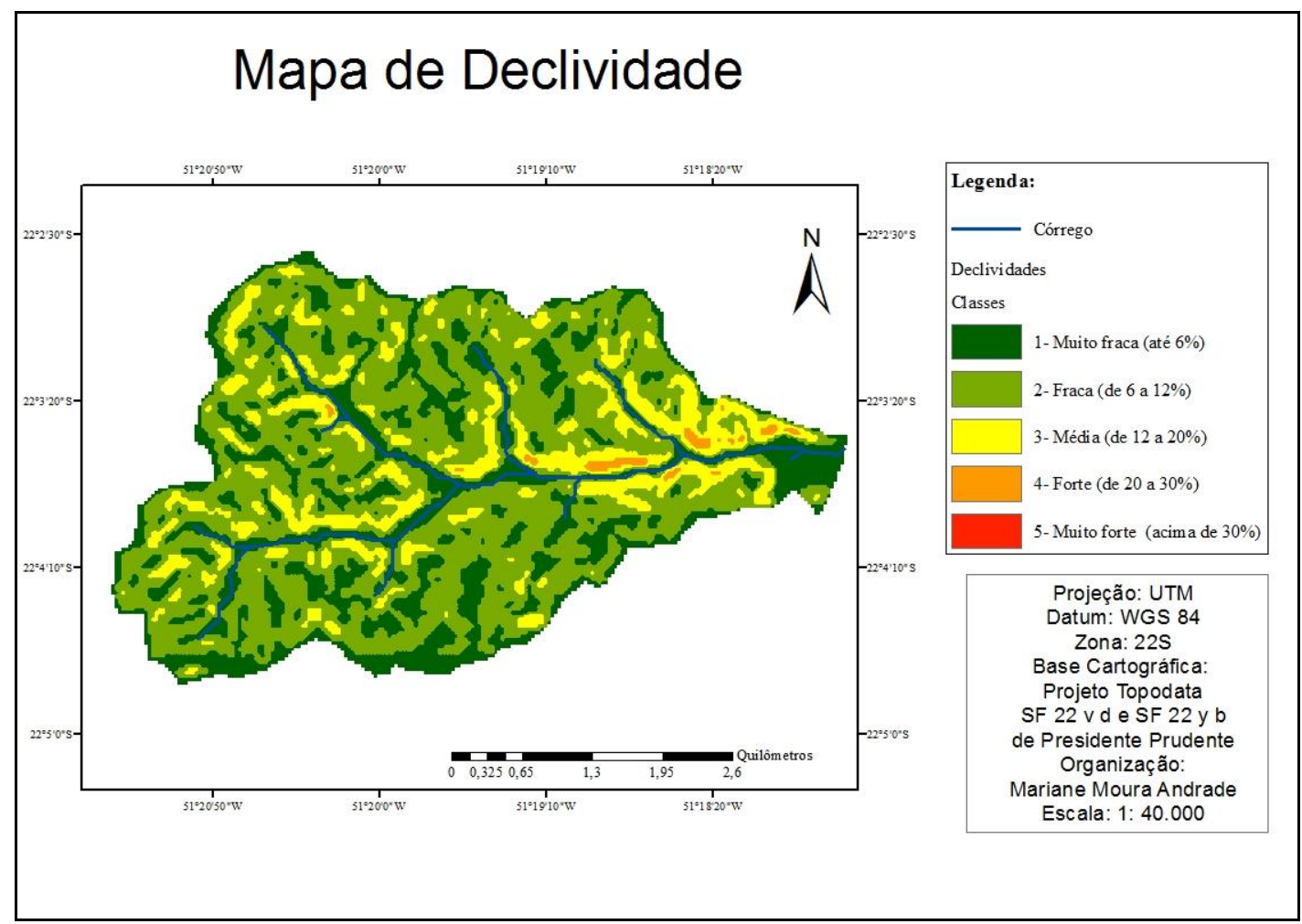

Figura 5. Classificação da Declividade da Bacia Hidrográfica do Córrego do Coqueiro. Presidente Prudente, SP, Brasil.

Figure 5. Classification of the Declivity of the Hydrographic Basin of Coqueiro Stream. Presidente Prudente, $S P$, Brazil.

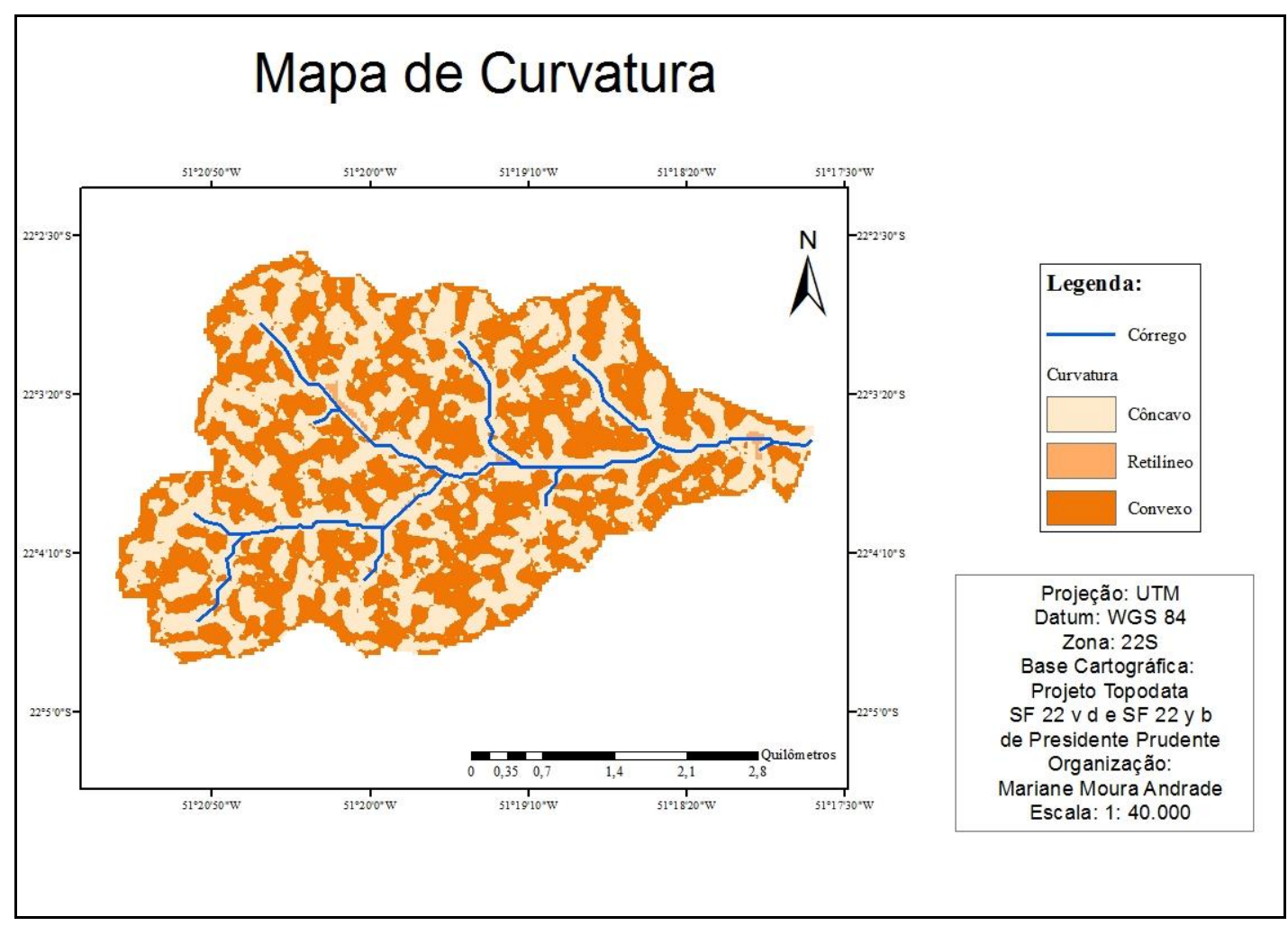

Figura 6. Classificação da Curvatura da Bacia Hidrográfica do Córrego do Coqueiro. Presidente Prudente, SP, Brasil.

Figure 6. Classification of the Curvature of the Hydrographic Basin of Coqueiro Stream. Presidente Prudente, SP, Brazil. 
Convém ainda destacar que, a partir da análise conjunta dos dados considerados determinantes no mapeamento da fragilidade ambiental, é possível intuir a influência que há entre os fatores utilizados como critérios na determinação da fragilidade ambiental.

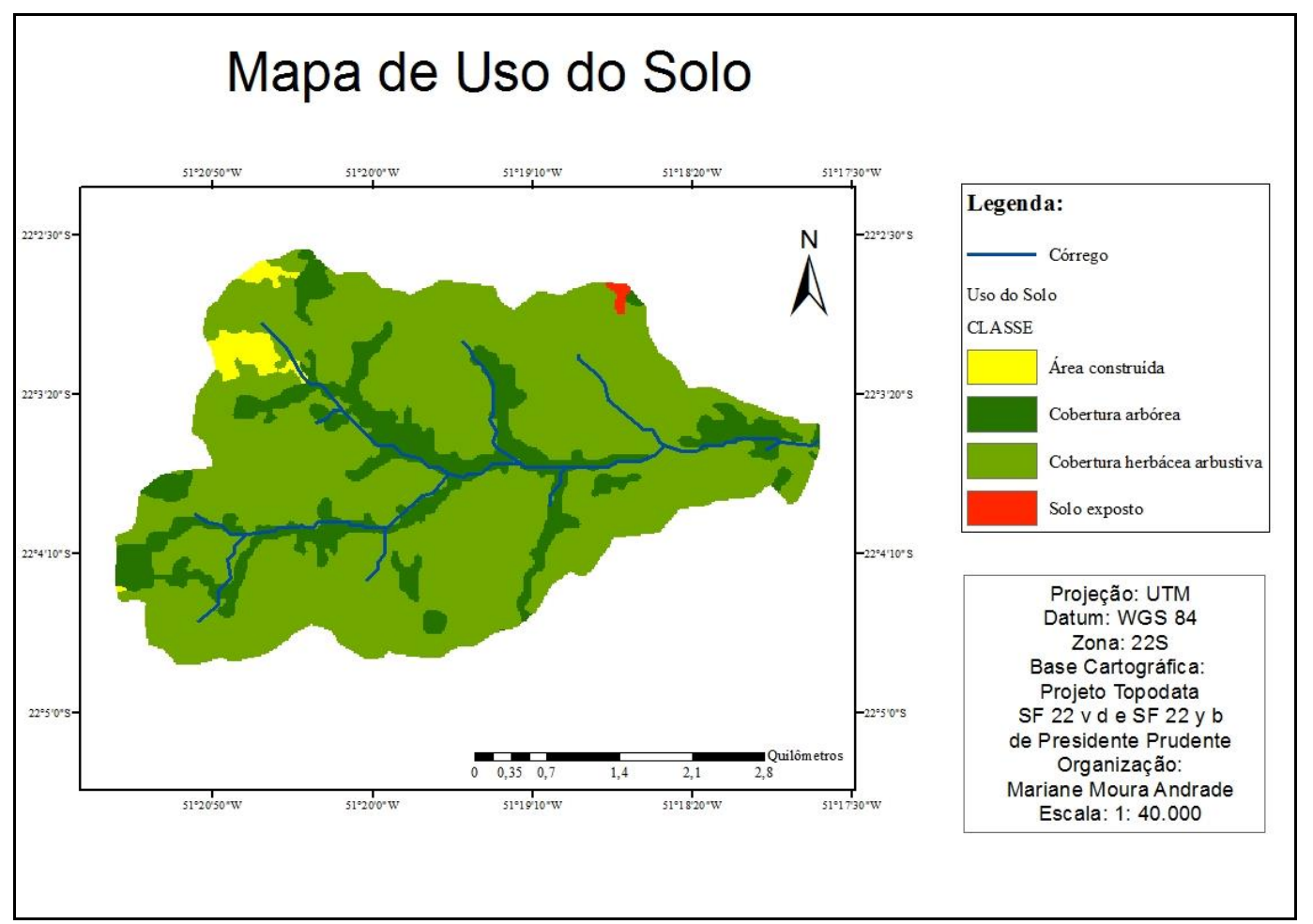

Figura 7. Classificação do Uso do Solo da Bacia Hidrográfica do Córrego do Coqueiro. Presidente Prudente, SP, Brasil.

Figure 7. Classification of the Use the Soil of the Hydrographic Basin of Coqueiro Stream, Presidente Prudente, SP, Brazil.

\section{CONCLUSÃO}

A fragilidade potencial, média e forte, ocorreram com maior intensidade nesta sub-bacia, onde há baixa densidade de matas, sendo que estas, juntamente com capoeiras normalmente são associadas aos cursos d'água.

A baixa proteção do solo pela pastagem é um dos fatores que leva ao processo de compactação, que aumenta o escoamento superficial e pode evoluir em sulcos causando erosão. As áreas de cultivo agrícola, as quais são representativas, expõe o solo com o cultivo, o que gera vulnerabilidade e não garantem proteção.

\section{REFERÊNCIAS}

BOIN MN. 2000. Chuvas e Erosões no Oeste Paulista: Uma Análise Climatológica Aplicada. Tese (Doutorado em Geociências e Meio Ambiente). Rio Claro: UNESP. 264p.

FRANCISCO FC. 1989. Análise ambiental e consequências do desmatamento no município de Presidente Prudente no período de 1917 a 1986. Dissertação (Mestrado em Geografia). Rio Claro: UNESP. 104p.

GONÇALVES GGG et al. 2011. Determinação da fragilidade ambiental de bacias hidrográficas. Floresta 41:797-808.

IBGE. 2010. Instituto Brasileiro de Geografia e Estatística. Disponível em: http://cidades.ibge.gov.br/xtras/perfil.php?codmun=354140 . Acesso em: 28 dez. 2015.

KAWAKUBO FS et al. 2005. Caracterização empírica da fragilidade ambiental utilizando geoprocessamento. In.: XII Simpósio Brasileiro de Sensoriamento Remoto. Anais...... Goiânia: INPE. P. 2203-2210.

MESSIAS CG et al. 2012. Análise empírica de fragilidade ambiental utilizando técnicas de geoprocessamento: o caso da área de influência da Hidrelétrica do Funil - MG. Revista Geonorte 2: 112-125.

MONTEIRO CAF. 1973. A dinâmica climática e as chuvas do estado de São Paulo: estudo geográfico sob forma de atlas. São Paulo: USP. 130p.

ROSS JLS. 1994. Análise empírica da fragilidade dos ambientes naturais e antropizados. Revista do Departamento de Geografia 8: 63-74.

SPÖRL C 2001. Análise da fragilidade ambiental relevo-solo com aplicação de três modelos alternativos nas altas 
Andrade et al.

bacias do Rio Jaguari-Mirim, Ribeirão do Quartel e Ribeirão da Prata. Dissertação (Mestrado em Geografia Física). São Paulo: USP. 159p.

SPÖRL C \& ROSS JLS 2004. Análise comparativa da fragilidade ambiental com aplicação de três modelos. Geousp Espaço e Tempo. p. 39-49. 